\title{
Jellyfish mucin may have potential disease-modifying effects on osteoarthritis
}

Naoshi Ohta1, Masato Sato*1, Kiminori Ushida², Mami Kokubo1, Takayuki Baba ${ }^{3}$, Kayoko Taniguchi², Makoto Urai ${ }^{2}$, Koji Kihira ${ }^{3}$ and Joji Mochida ${ }^{1}$

Address: ${ }^{1}$ Department of Orthopaedic Surgery, Surgical Science, Tokai University School of Medicine, 143 Shimokasuya, Isehara, Kanagawa 259-

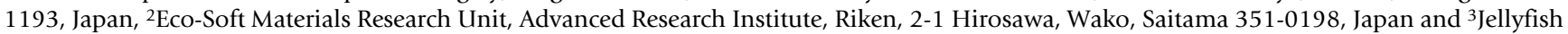
Research Laboratories, Inc, KSP E513 Sakado 3-2-1, Takatsu-ku, Kawasaki, Kanagawa 213-0012, Japan

Email: Naoshi Ohta - naoshi-o@is.icc.u-tokai.ac.jp; Masato Sato* - sato-m@is.icc.u-tokai.ac.jp; Kiminori Ushida - kushida@riken.jp; Mami Kokubo - mami-k@is.icc.u-tokai.ac.jp; Takayuki Baba - takayuki_baba@jfish-lab.com; Kayoko Taniguchi - kytaniguchi@riken.jp; Makoto Urai - maurai@riken.jp; Koji Kihira - kouji_kihira@jfish-lab.com; Joji Mochida - jomo@is.icc.u-tokai.ac.jp

* Corresponding author

Published: 8 December 2009

BMC Biotechnology 2009, 9:98 doi:10.1 186/1472-6750-9-98
Received: 7 April 2009

Accepted: 8 December 2009

This article is available from: http://www.biomedcentral.com/1472-6750/9/98

(C) 2009 Ohta et al; licensee BioMed Central Ltd.

This is an Open Access article distributed under the terms of the Creative Commons Attribution License (http://creativecommons.org/licenses/by/2.0), which permits unrestricted use, distribution, and reproduction in any medium, provided the original work is properly cited.

\begin{abstract}
Background: We aimed to study the effects of intra-articular injection of jellyfish mucin (qniumucin) on articular cartilage degeneration in a model of osteoarthritis (OA) created in rabbit knees by resection of the anterior cruciate ligament. Qniumucin was extracted from Aurelia aurita (moon jellyfish) and Stomolophus nomurai (Nomura's jellyfish) and purified by ion exchange chromatography. The OA model used 36 knees in 18 Japanese white rabbits. Purified qniumucin extracts from S. nomurai or A. aurita were used at $1 \mathrm{mg} / \mathrm{ml}$. Rabbits were divided into four groups: a control $(\mathrm{C})$ group injected with saline; a hyaluronic acid $(\mathrm{HA})$-only group $(\mathrm{H}$ group); two qniumucin-only groups (M groups); and two qniumucin + HA groups (MH groups). One milligram of each solution was injected intra-articularly once a week for 5 consecutive weeks, starting from 4 weeks after surgery. Ten weeks after surgery, the articular cartilage was evaluated macroscopically and histologically.

Results: In the $C$ and $M$ groups, macroscopic cartilage defects extended to the subchondral bone medially and laterally. When the $\mathrm{H}$ and both $\mathrm{MH}$ groups were compared, only minor cartilage degeneration was observed in groups treated with qniumucin in contrast to the group without qniumucin. Histologically, densely safranin-O-stained cartilage layers were observed in the $\mathrm{H}$ and two $\mathrm{MH}$ groups, but cartilage was strongly maintained in both $\mathrm{MH}$ groups.
\end{abstract}

Conclusion: At the concentrations of qniumucin used in this study, injection together with HA inhibited articular cartilage degeneration in this model of OA.

\section{Background}

Osteoarthritis $(\mathrm{OA})$ is one of the most common joint diseases and is characterized by the gradual degeneration of cartilage over a long time (regressive degeneration). This disease commonly develops in the weight-bearing joints of the lower limbs, such as the knee and hip joints, and onset shows a close correlation closely with age. OA is thus one of the main causes of pain and joint dysfunction 
among the elderly, and is also often seen in young people after traumas such as a fracture, anterior cruciate ligament transection (ACL-T), meniscus injury or in the presence of an underlying disease such as hemophilia [1]. Currently, pharmacotherapies for OA focus mainly on the alleviation of pain and consist of systemic analgesic therapies and local intra-articular treatments. Nonsteroidal antiinflammatory drugs (NSAIDs) are widely used as systemic analgesic therapies [2]. However, pathological progression of OA can be accelerated by the use of NSAIDs [3-6]. Similarly, hyaluronan (HA) injection therapy is a widely recognized part of local intra-articular treatments, inhibiting the destruction of articular cartilage by increasing the viscosity of synovial fluid [7-10].

The presence of a thin membrane layer on the articular cartilage surface is believed to protect against external impact and reduce friction. This membrane is formed from glycoproteins with a mucin-type domain, some of which have been identified in humans, including tribonectin and lubricin $[11,12]$. These glycoproteins in the joints show tandem repeat regions composed of 7-8 amino acids in the mucin domain; more than $90 \%$ of the threonines and serines can form $O$-glycosyl bonds and are glycosylated. The sugar chains are short, consisting of 2-3 monosaccharides (including sialic acid), with very little diversity (glycoforms) in the sugar chains. These mucins display characteristics very similar to those of qniumucin, the jellyfish mucin analyzed in this study.

At present, no methods have been established to produce mucins artificially on a sufficiently large scale for therapeutic use. Chemical synthesis is not very practical, as the cost of producing a mucin-type polymer is high, even when the structure is very simple. Although $O$-glycosylation is a typical posttranslational modification in biological systems, occurring in the Golgi apparatus, synthetic versions of this procedure, in which sugar chains are attached after the expression of core proteins, can only be performed in a limited manner. Under these circumstances, extraction of natural abundant mucins from organisms is most often used. In the industrial production of mucins, only extraction from the gastric juices or saliva of domestic animals has proven commercially successful. However, the purity and homogeneity of these mucins are insufficient for use as a single substance and they have been further avoided since the discovery of bovine spongiform encephalopathy (BSE) [13]. Mucins have also been extracted from marine creatures, such as starfish [14] and squid [15], but this technique is also ineffective in terms of efficiency and cost.

Stomolophus nomurai is the world's largest jellyfish, growing to over $1 \mathrm{~m}$ in diameter and weighing more than 200 $\mathrm{kg}$ (Fig. 1). Vast proliferation of this species has been

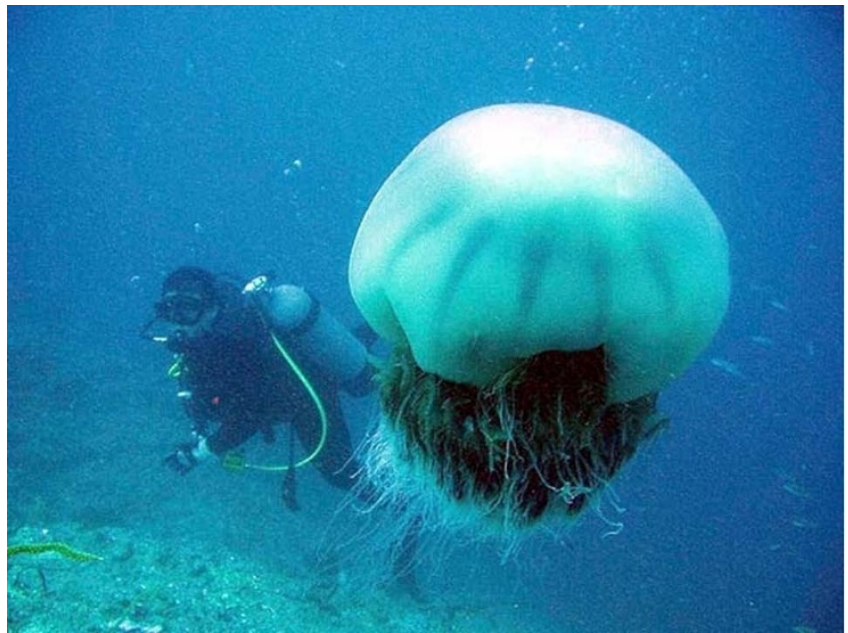

Figure I

Nomura's jellyfish. The world's largest jellyfish, growing to over I $\mathrm{m}$ in diameter and weighing more than $200 \mathrm{~kg}$.

reported in the coastal regions of the Sea of Japan. Massive smacks of jellyfish (about 100 tons on 1 day at one site) are caught in fishing nets, significantly interfering with the fishing industry. Removal of these jellyfish has now become a routine practice for power plants, industrial facilities, fisheries and harbors in coastal areas, and handling such large quantities of jellyfish is extremely difficult. On the positive side, Ushida et al. have discovered and successfully isolated a novel mucin derived from many species of jellyfish, including $S$. nomurai [16]. This compound, qniumucin, is low in diversity and high in purity and constitutes an exceptional mucin that can be obtained industrially as a homogeneous product.

In this study, we discuss the effects of intra-articular injection of qniumucin on cartilage degeneration in a rabbit model of OA.

\section{Results}

\section{Macroscopic study}

Advanced cartilage defects extending to the subchondral bone were observed on both the medial and lateral sides in group C (Fig. 2a). Similar results were observed in group $M$, with no apparent differences between groups $C$ and $\mathrm{M}$ (Fig. 2a, c, d). In a comparison of groups $\mathrm{H}$ and $\mathrm{MH}$, less cartilage degeneration was observed in the groups treated with qniumucin and HA than in the group treated with HA alone (Fig. 2b, e, f).

\section{Histological study}

Exposure of subchondral bone was detected by safranin$\mathrm{O}$ staining in group C (Fig. 3a). No cartilaginous layer with metachromasia shown by toluidine blue staining was observed in group C (Fig. 3g). Fissures in the cartilage 

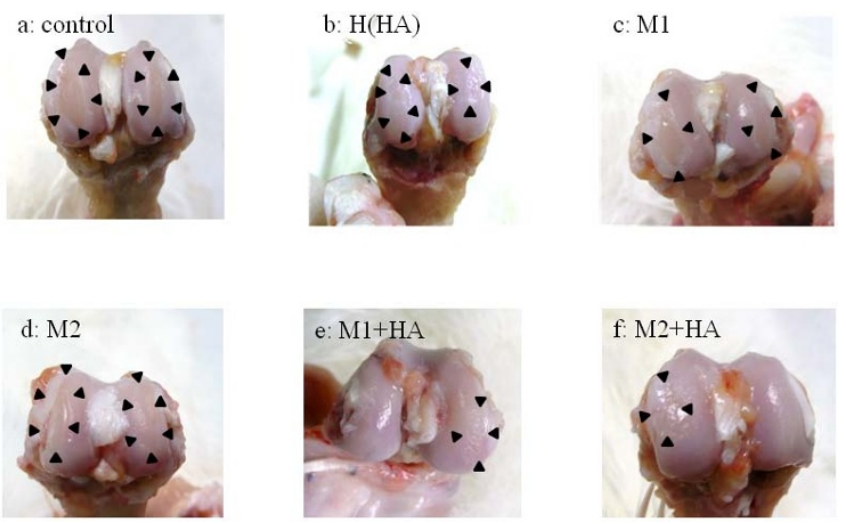

Figure 2

Macroscopic findings in the femur of the knee joint 10 weeks after OA model preparation. a (group C): Cartilage defects are observed on both the medial and lateral sides. These extend to the subchondral bone and range across the entire weight-bearing area. b (group H): Irregularity of the cartilage surface is apparent on both medial and lateral sides in the photo. A cartilage defect extending to the subchondral bone can be seen in some sections. c, $\mathbf{d}$ (group MI, moon jellyfish extract; group M2, Nomura's jellyfish extract, respectively): As with group $\mathrm{C}$, a cartilage defect extending to the subchondral bone is observed. No difference is apparent in the range of the defect. e, $\mathbf{f}$ (group $\mathrm{MHI}$, moon jellyfish extract; group $\mathrm{MH} 2$, Nomura's jellyfish extract, respectively): Irregularity of the cartilage surface is apparent on the medial side in the photo. No exposure of the subchondral bone is observed and the range of the defect is very limited. No differences are seen in the $\mathrm{M}$ or $\mathrm{MH}$ groups where the qniumucin had been extracted from the two different species of jellyfish. Arrowheads indicate areas of exposed subchondral bone.

layers and reduced stainability were observed in group $\mathrm{H}$ (Fig. 3b). Slight metachromasia in the cartilage layer was observed in group $\mathrm{H}$ (Fig. $3 \mathrm{~h}$ ). In group $\mathrm{M}$, minimal residual cartilage layers were present, but no staining was observed and the cartilage cells had been destroyed (Fig. $3 c, d)$. As in group $\mathrm{C}$, no metachromatic cartilage layer was observed in group M (Fig. 3i, j). Erosion of the cartilage, fissures and reduced staining were observed in group $\mathrm{MH}$. However, compared with group $\mathrm{H}$, the fissures were shallower and more cells were present (Fig. 3e, f). No metachromasia was observed in the cartilage layer in group MH (Fig. 3k, l).

Average OA scores were: group C, $22.00 \pm 4.00$; group $\mathrm{H}$, $11.17 \pm 4.65$; group $M 1,18.67 \pm 1.15$; group $M 2,18.00 \pm$ 0.00 ; group $\mathrm{MH} 1,4.33 \pm 4.16$; and group $\mathrm{MH} 2,7.00 \pm$ 2.65. Groups $\mathrm{C}, \mathrm{M} 1$ and M2 did not differ significantly. Significant differences were observed between groups $\mathrm{H}$ and $\mathrm{C}$, between groups $\mathrm{H}$ and $\mathrm{M} 1$ or $\mathrm{M} 2$, between groups $\mathrm{H}$ and $\mathrm{MH} 1$, and between groups $\mathrm{M} 1$ or $\mathrm{M} 2$ and groups MH1 or MH2 $\left({ }^{*} P<0.05\right)$ (Fig. 4, Table 1$)$.

\section{Discussion}

This study examined the effects of intra-articular injection of qniumucin in a rabbit model of OA using resection of the anterior cruciate ligament. The results were as follows. First, when qniumucin alone was injected, cartilage degeneration did not differ from that in the control group. Second, only minor cartilage degeneration was observed when a mixture of HA and qniumucin was injected compared with the degeneration present after injection of HA only. Third, no significant difference in the effects of qniumucin isolated from different species of jellyfish was apparent in this study.

HA is responsible for the viscosity and elasticity of synovial fluid and thus plays roles in lubrication and shockabsorption. An increase in low molecular weight HA reportedly reduces the viscosity and elasticity of synovial fluid under inflammatory conditions such as OA [17]. However, various other effects have been attributed to HA, including anti-inflammatory and analgesic effects, inhibition of cartilage degeneration and an ability to enhance damage repair [18].

Safranin-O staining reflects the accumulation of proteoglycan and acts as an index of cartilage degeneration in tissues. Although a reduction in safranin-O staining of the extracellular matrix was seen in our study, cartilage degeneration was clearly inhibited in groups $\mathrm{H}$ and $\mathrm{MH}$ compared with the degeneration observed in group $\mathrm{C}$.

In recent years, a glycoprotein with a mucin region called lubricin (a superficial zone protein and member of the tribonectin family) has been identified in the synovial fluid and on the articular surface. The presence of lubricin in both areas contributes to reductions in articular friction. This substance is characterized by a mucin-type region in which $O$-glycans are connected to the protein backbone, with nonmucin-type sequences at both ends. This nonmucin region has been suggested to interact with the cartilage surface to facilitate the adherence of lubricin. The mucin and nonmucin regions are assumed to play different roles, with the former extending the sugar chains outward like a brush to reduce friction and the latter promoting adhesion of lubricin to the cartilage surface. This is referred to as the "brushing model", based on the inferred shape of the molecule [19]. No such mechanism has been suggested for tribonectin, but this substance shares some common characteristics with lubricin insofar as it also displays a mucin-type sequence that reduces friction together with a nonmucin region. The mucin region is believed to adsorb densely to the cartilage tissue surface (perhaps as a film) to reduce friction. However, adhesion of these mucin-type glycoproteins to the articular surface after injection has yet to be directly confirmed. 

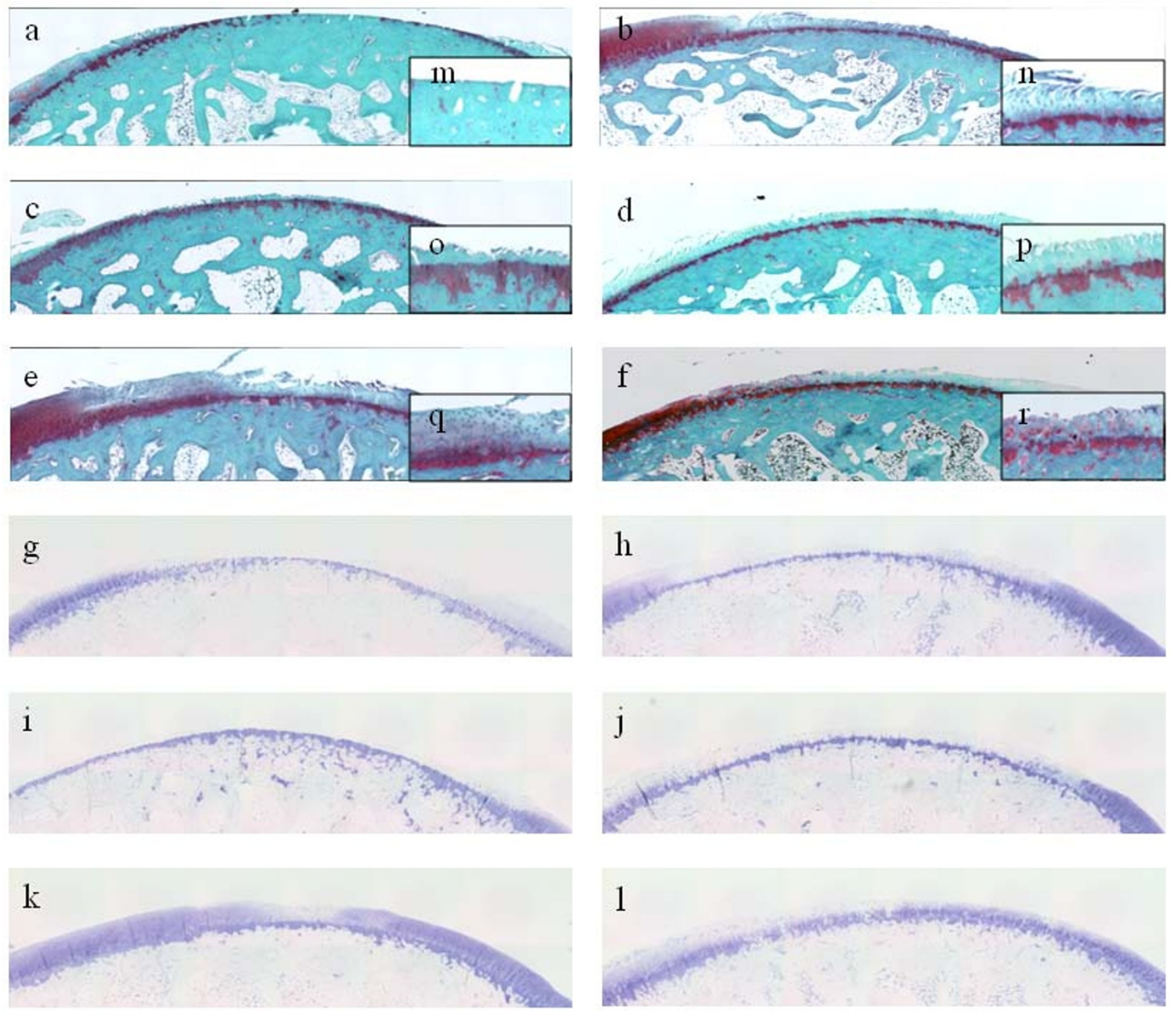

\section{Figure 3}

Histological findings. The femoral condyle in the knee joint was resected and fixed in $4 \%$ neutral-buffered formalin ( $\mathrm{pH}$ 7.4). The tissue was then decalcified with 10\% EDTA and the cross-section was embedded in paraffin wax. Dewaxed sections were processed for safranin-O (a--f) and toluidine blue (g--l) staining. a (group C): The cartilage defect reaches the subchondral bone. b (group H): The fissure in the cartilage extends to the deep layer and reduced staining is observed in the upper layer from the tide mark. Cell sequences are not maintained and a reduction in the number of cells is observed. c, $\mathbf{d}$ (group MI, moon jellyfish extract; group M2, Nomura's jellyfish extract, respectively): Only a small portion of the cartilage layer remains and the cells have been obliterated. e, $\mathbf{f}$ (group MHI, moon jellyfish extract; group MH2, Nomura's jellyfish extract, respectively): Peeled cartilage layers are seen, but fissure have generally extended to the middle layer. Cell sequences are relatively well maintained and the reduction in staining is minor compared with that in group H. $\mathbf{g}$ (group C): No metachromasia is observed with toluidine blue staining in the cartilage layer. $\mathbf{h}$ (group H): Slight metachromasia is observed in the cartilage layer. $\mathbf{i}, \mathbf{j}$ (group MI, moon jellyfish extract; group M2, Nomura's jellyfish extract, respectively): No metachromasia is observed in the cartilage layer. k, I (group MHI, moon jellyfish extract; group MH2, Nomura's jellyfish extract, respectively): The cartilage layer shows metachromasia with toluidine blue staining, which is specific for articular cartilage. Magnification: a-l, $\times 4 ; \mathrm{m}-\mathrm{r}, \times 10$. 
Table I: Results of post hoc testing (Scheffé's method).

\begin{tabular}{|c|c|c|c|c|c|c|c|}
\hline \multirow[t]{2}{*}{ (I) $\mathrm{VI}$} & \multirow[t]{2}{*}{ (J) VI } & \multirow[t]{2}{*}{ Difference of averages (I-J) } & \multirow[t]{2}{*}{ SEM } & \multirow[t]{2}{*}{$\mathbf{P}$} & \multicolumn{2}{|c|}{$95 \% \mathrm{Cl}$} & \multirow[b]{2}{*}{ Figure 5} \\
\hline & & & & & Lower limit & Upper limit & \\
\hline \multirow[t]{5}{*}{ Group C } & group MHI & $17.6667^{*}$ & 2.3094 & .000 & 11.891 & 23.443 & $* 2$ \\
\hline & group $\mathrm{MH} 2$ & $15.0000 *$ & 2.3094 & .000 & 9.224 & 20.776 & $* 1$ \\
\hline & group $\mathrm{H}$ & $10.8333 *$ & 2.3094 & .002 & 5.057 & 16.609 & $* 5$ \\
\hline & group MI & 3.3333 & 2.3094 & .233 & -2.443 & 9.109 & \\
\hline & group M2 & 4.0000 & 2.3094 & .157 & -1.776 & 9.776 & \\
\hline \multirow[t]{5}{*}{ Group H } & group MHI & $6.8333^{*}$ & 2.6822 & .024 & 1.057 & 12.609 & $* 10$ \\
\hline & group $\mathrm{MH} 2$ & 4.1667 & 2.6822 & .142 & -1.609 & 9.943 & \\
\hline & group C & $-10.8333 *$ & 2.6822 & .002 & -16.609 & -5.057 & $* 5$ \\
\hline & group MI & $-7.5000^{*}$ & 2.6822 & .015 & -13.276 & -1.724 & $* 4$ \\
\hline & group M2 & $-6.8333^{*}$ & 2.6822 & .024 & -12.609 & -1.057 & $* 3$ \\
\hline \multirow[t]{5}{*}{ Group MI } & group MHI & |4.3333* & 0.6667 & .000 & 8.557 & 20.109 & $* 9$ \\
\hline & group $\mathrm{MH} 2$ & II.6667* & 0.6667 & .001 & 5.891 & 17.443 & $* 8$ \\
\hline & group H & $7.5000 *$ & 0.6667 & .015 & 1.724 & 13.276 & $* 4$ \\
\hline & group C & -3.3333 & 0.6667 & .233 & -9.109 & 2.443 & \\
\hline & group M2 & .6667 & 0.6667 & .806 & -5.109 & 6.443 & \\
\hline \multirow[t]{5}{*}{ Group M2 } & group MHI & $13.6667^{*}$ & 0.0000 & .000 & 7.891 & 19.443 & $* 7$ \\
\hline & group $\mathrm{MH} 2$ & $11.0000 *$ & 0.0000 & .001 & 5.224 & 16.776 & $* 6$ \\
\hline & group H & $6.8333^{*}$ & 0.0000 & .024 & 1.057 & 12.609 & $* 3$ \\
\hline & group C & -4.0000 & 0.0000 & .157 & -9.776 & 1.776 & \\
\hline & group MI & -.6667 & 0.0000 & .806 & -6.443 & 5.109 & \\
\hline \multirow[t]{5}{*}{ Group } & group $\mathrm{MH} 2$ & -2.6667 & 2.4037 & .334 & -8.443 & 3.109 & \\
\hline & group H & $-6.8333^{*}$ & 2.4037 & .024 & -12.609 & -1.057 & $* 10$ \\
\hline & group C & $-17.6667^{*}$ & 2.4037 & .000 & -23.443 & $-|1.89|$ & $* 2$ \\
\hline & group MI & $-14.3333^{*}$ & 2.4037 & .000 & -20.109 & -8.557 & *9 \\
\hline & group M2 & $-13.6667 *$ & 2.4037 & .000 & -19.443 & -7.891 & $* 7$ \\
\hline
\end{tabular}


Table I: Results of post hoc testing (Scheffé's method). (Continued)

\begin{tabular}{llllllll}
\hline Group MH2 & group MHI & 2.6667 & 1.5275 & .334 & -3.109 & 8.443 \\
\cline { 2 - 7 } & group H & -4.1667 & 1.5275 & .142 & -9.943 & 1.609 \\
\cline { 2 - 7 } & group C & $-15.0000 *$ & 1.5275 & .000 & -20.776 & -9.224 & $* 1$ \\
& $\begin{array}{llllll}\text { group MI } \\
\text { group M2 }\end{array}$ & $-11.6667 *$ & 1.5275 & .001 & -17.443 & -5.891 & $* 8$ \\
& & $-11.0000 *$ & 1.5275 & .001 & -16.776 & -5.224 & $* 6$ \\
\hline
\end{tabular}

SEM, standard error of the mean; $\mathrm{Cl}$, confidence interval.

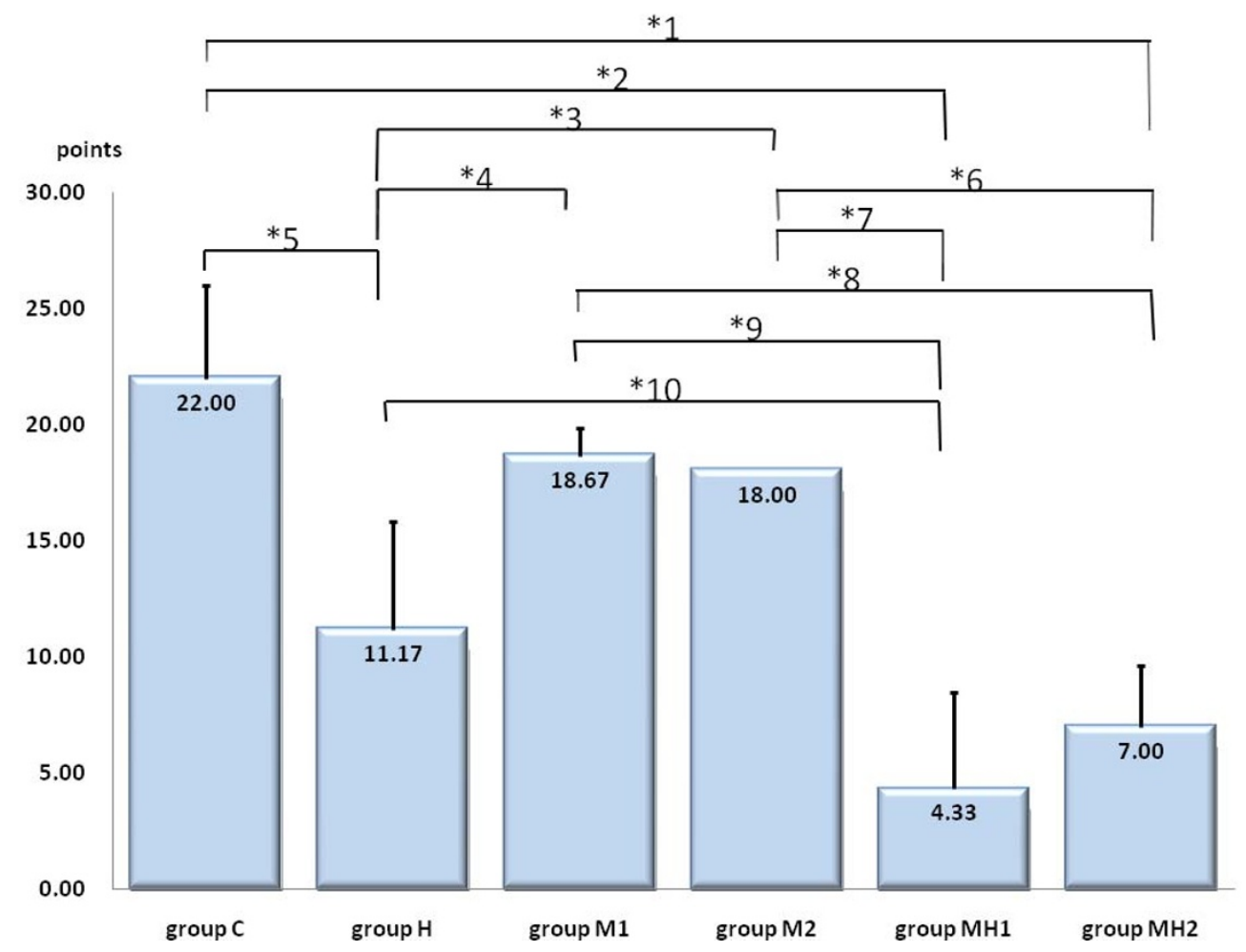

Figure 4

Osteoarthritis score. Samples were histologically evaluated based on the standard grading and staging of OA cartilage histopathology. Evaluation was quantified using the following formula: most degenerated site in the cartilage (grades I-6, Table 2) $x$ area of degeneration (stages I-4, Table 3) $=$ OA score (I-24, Table 3). Columns and vertical lines represent mean values and standard deviations for each group, respectively. No significant differences were observed between group $\mathrm{C}$ and groups $\mathrm{MI}$ and M2. Significant differences were observed between groups $\mathrm{H}$ and $\mathrm{C}$, between groups $\mathrm{H}$ and $\mathrm{MI}$ or $\mathrm{M} 2$, between groups $\mathrm{H}$ and $\mathrm{MHI}$, and between groups $\mathrm{MI}$ or $\mathrm{M} 2$ and groups $\mathrm{MHI}$ or $\mathrm{MH} 2$. *Significant differences between groups, corresponding to the last column in Table I. After analysis of variance, least significant differences were used for post hoc testing (Scheffé's method). Mean OA scores were compared and values of $* P<0.05$ were considered significant. Groups MI and MHI: moon jellyfish extract. Groups M2 and MH2: Nomura's jellyfish extract. 
Mucin or mucin-like substances are likely to form a selfassembled film (SAF) on both hydrophobic and hydrophilic surfaces. One significant example of a SAF in biological systems is the mucin film on the ocular surface that protects the eyeball [20]. Although the bond created by each single sugar chain makes only a small contribution to the total adsorption energy, cooperative interaction of many glycan chains concentrated in a small area provides a sufficient gain in free energy (and a reduction in entropy) to immobilize the polymer chain of the mucin. Adhesion and SAF formation on the surface are possible without any selective interaction, such as that suggested for the nonmucin sequence of lubricin, which may be the first trigger of adhesion. Therefore, if the goal of treatment is to reduce friction, any kind of mucin that lacks a nonmucin region could be used instead of lubricin or tribonectin. Jay mentioned the synergic effects of lubricin and HA in an in vitro study [12]. Mucin may have potential synergic effects with HA, as mucin is one component of lubricin. In this study, we first demonstrated that exogenous mucin derived from natural jellyfish showed synergic effects with HA using an in vivo animal model. These effects might be induced by improving the viscosity and friction properties of synovial fluid and enhancing the self-assembly capacity of cartilage.

Many different kinds of mucins are known. As no largescale production of artificial polymeric mucins has been achieved with biotechnology or chemical synthesis, extraction from the natural environment remains the most appropriate method for provision as commercial substances. Mucins are widely distributed in animals and plants as components of mucus. For example, in plants mucins are found in extracts of lotuses, okra and yams. However, the structure of plant mucins is completely different from that of animal mucins, with a short peptide connected to long sugar chains, such as galactan and mannan [21]. We have therefore focused on animal mucins as candidate materials for therapeutic injection.

Animal mucins are produced and retained as components of mucus by all living animals, regardless of taxonomy. Huge potential variations exist in components such as the core peptide sequence, nonmucin domain sequence and structure of the sugar chains (glycoforms) according to the animal species. However, there are very few examples of animal mucins that are mass produced by domestic animals [13]. These are broadly classified as gastric mucins [22] and submaxillary salivary gland mucins $[23,24]$. Gastric mucins constitute a mixture harvested from the lavage fluids of internal organs as low-purity materials. Only total monosaccharide (for example, sialic acid) and amino acid analyses have been performed, with no further characterization, so gastric mucins constitute an inexpensive material suitable for mass production. In contrast, submaxillary mucins are very pure and detailed structural analyses of their amino acid sequences and saccharide compositions have been performed [25]. A monoclonal antibody directed against submaxillary mucins known as sialyl Tn antigen has been produced and used as a tumor marker [26]. However, these animal mucins risk contamination with foreign substances unless thorough purification is performed, so use tends to be avoided. For example, prions causing BSE cannot be eliminated. Mucins from snails [27], starfish [14] and squid [15] are currently available on the market, but production volumes are limited. Among these mucin alternatives, qniumucin, which is harvested from jellyfish, was discovered in recent years by our colleagues [16]. As mass production is inexpensive, qniumucin is a candidate mucin for wide application in many patients as a treatment for OA. Qniumucin is characteristically an almost pure monotonously repeated sequence of short mucin regions called "tandem repeats". The tandem repeat unit consists of eight amino acids (sequence VVETTAAP or VIETTAAP) and the sugar chains are short (usually only 1-3 sugars), with only a few types of monosaccharides and no sialic acid. Since qniumucin seems to have very few peptide sequences other than the mucin portion, only mild biological reactions are expected from the immune system in the form of allergies. This low potential for biological rejection is a further advantage of the use of this mucin. The risks involved in providing a mass product on an industrial scale are thus significantly reduced.

In a preliminary experiment to test the effects of injection with qniumucin, no elevation of the blood cell count or C-reactive protein and no swelling of the joints were observed (unpublished results). No histological findings of synovium have been detected among normal and injected joints (unpublished results). The possibility that an endogenous endotoxin, identified in this preliminary experiment, might cause adverse effects is a concern, but no such effects have yet been observed. After the purification method was improved to preclude any contamination with the solvent from high-performance liquid chromatography, the concentration of endotoxin in qniumucin purified by ion-exchange chromatography and in unpurified qniumucin were both $<10 \mathrm{EU} / \mathrm{ml}$ when characterized by Endosafe-PTS (Charles River Laboratories Japan, Kanagawa, Japan). Based on these considerations, we proceeded with the intra-articular injection of this qniumucin, expecting a friction-reducing effect. The present results represent a promising step in the development of a new treatment for cartilage degeneration.

\section{Conclusion}

After injecting a mixture of mucin and HA, cartilage degeneration was significantly inhibited compared with that in rabbits injected with HA alone. This effect might be 
induced by improving the viscosity and friction properties of the synovial fluid and enhancing the self-assembly capacity of the cartilage.

\section{Methods}

All procedures using animals in this study were performed in accordance with the Guide for the Care and Use of Laboratory Animals (NIH Publication No. 85-23, revised 1996) published by the National Institutes of Health, USA, and the Guidelines of Tokai University on Animal Use.

\section{Reagents}

$\operatorname{Artz}^{\circledast}$ (Kaken Pharmaceutical, Tokyo, Japan) was used in making the solution of polymeric HA. The average molecular weight of this HA is approximately 800,000 and the concentration used was $25 \mathrm{mg} / 2.5 \mathrm{ml}$. Qniumucin from S. nomurai or A. aurita was dissolved in saline at a concentration of $1 \mathrm{mg} / \mathrm{ml}$ to create stock solutions.

\section{Extraction and purification of qniumucin}

The mesogloea, the major part of the umbrella in jellyfish, was cut into small pieces and suspended in water. After removing insoluble material by centrifugation at 10,000 $\times$ $g$, one third of the volume of ethanol was added to the supernatant. The resulting precipitate was harvested by centrifugation at $10,000 \times g$ and dissolved in water. Supernatant was collected by centrifugation at $10,000 \times g$, dialyzed against water, and lyophilized. The lyophilized material was then dissolved in phosphate buffer and incubated with anion-exchange gel beads (Diethylaminoethyl (DEAE) - resin, Toyopearl DEAE-650M; Tosoh, Tokyo, Japan) for $1 \mathrm{~h}$. The beads were washed well with phosphate buffer and the bound proteins were eluted with elution buffer (phosphate buffer, $0.5 \mathrm{M} \mathrm{NaCl}$ ). The eluent was collected by filtration, dialyzed against water, and lyophilized.

\section{Animals}

Japanese white rabbits (females weighing $3 \mathrm{~kg}$ ) were purchased from Tokyo Laboratory Animals Science (Tokyo, Japan). The rabbits were kept individually and reared in a fiber-reinforced polymer cage (width $450 \mathrm{~mm} \times$ height $450 \mathrm{~mm} \times$ depth $900 \mathrm{~mm}$ ).

\section{OA model}

An ACL-T model [28-34] was prepared for use as the OA model. With the rabbits under inhalation anesthesia with isoflurane (Forane ${ }^{\varpi}$; Abbott Japan, Tokyo, Japan), a 3-cm incision was made aseptically on the medial side of both knees to expose the patella and patellar tendon, and the articular capsule was incised. The patella was then dislocated outwardly to an extended position and the knee joint was bent for macroscopic resection of the anterior cruciate ligament. The patella was then repositioned and the subdermal muscular layer and skin were sutured with nylon thread.

\section{Experimental design}

Eighteen rabbits in which the 36 anterior cruciate ligaments had been resected in both knee joints were divided randomly into four groups: a control (C) group (injected with saline; six knees), an HA-only group (H group; six knees), two qniumucin-only groups (M1:S. nomurai, M2:A. aurita group; six knees each) and two qniumucin + HA groups (MH1 and MH2 groups; six knees each). Each treatment comprised $1 \mathrm{ml}$ per intra-articular injection. Purified qniumucin from $S$. nomurai or A. aurita was used at $1 \mathrm{mg} / \mathrm{ml}$. Mixtures of HA solution $(0.5 \mathrm{ml})+$ saline $(0.5$ $\mathrm{ml})$, qniumucin solution $(0.5 \mathrm{ml})+$ saline $(0.5 \mathrm{ml})$ and qniumucin solution $(0.5 \mathrm{ml})+\mathrm{HA}$ solution $(0.5 \mathrm{ml})$ were injected into the $\mathrm{H}, \mathrm{M}$ and $\mathrm{MH}$ groups, respectively, after resection of the anterior cruciate ligament. These four treatments were given at intervals of 7 days, starting from week 4 after surgery (thus in weeks 4, 5, 6, 7 and 8; Fig. 5). With each rabbit under isoflurane inhalation anesthesia, the intra-articular injection was made into the upper margin of the lateral patella in the rabbit knee joint, using a syringe with a 26-G needle (Terumo, Tokyo, Japan). All rabbits were killed by pentobarbiturate overdose (Nembutal $^{\circledast ;}$ Dainippon Sumitomo Pharma, Osaka, Japan) in week 10 after resection (Fig. 5).

\section{Macroscopic and histological evaluation of the articular cartilage}

The femoral knee joint was checked immediately after the rabbits had been killed. The femora of both knee joints were resected and fixed in $4 \%$ neutral-buffered formalin ( $\mathrm{pH}$ 7.4). Fixed samples were decalcified with $10 \%$ ethylene diaminetetraacetic acid (EDTA) ( $\mathrm{pH}$ 7.4) and then embedded in paraffin wax. Sections cut in the sagittal plane of the femoral condyle were dewaxed, prepared and

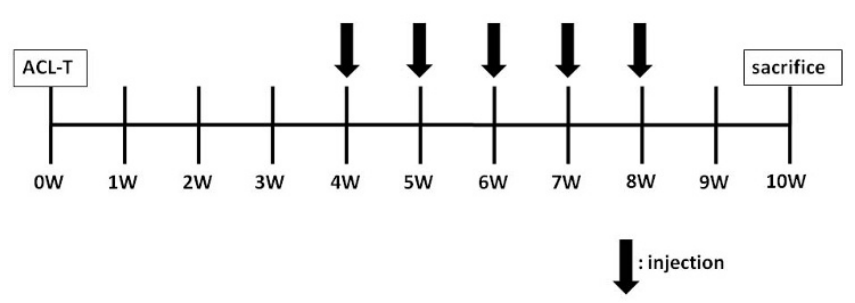

Figure 5

Protocol. Intra-articular injections were commenced from week 4 after preparation of the osteoarthritis (OA) model. Treatment solutions were injected once weekly until week 8. The rabbits were killed 10 weeks after surgery. Surgery and intra-articular injections were performed with the rabbits under general anesthesia. ACL-T, anterior cruciate ligament transection. 
Table 2: OA cartilage histopathology grade assessment; grading methodology

\begin{tabular}{|c|c|c|c|c|}
\hline Grade (key feature) & \multicolumn{4}{|l|}{ Associated criteria (tissue reaction } \\
\hline Grade I: surface intact & \multicolumn{4}{|c|}{$\begin{array}{l}\text { Matrix: superficial zone intact, oedema and/or superficial fibrillation (abrasion), focal superficial matrix } \\
\text { condensation } \\
\text { Cells: death, proliferation (clusters), hypertrophy, superficial zone Reaction must be more than superficial } \\
\text { fibrillation only }\end{array}$} \\
\hline Grade 2: surface discontinuity & \multicolumn{4}{|c|}{$\begin{array}{l}\text { As above } \\
+ \text { Matrix discontinuity at superficial zone (deep fibrillation) } \\
\pm \text { Cationic stain matrix depletion (Safranin O or Toluidine Blue) upper I/3 of cartilage } \\
\pm \text { Focal perichondronal increased stain (mid zone) } \\
\pm \text { Disorientation of chondron columns } \\
\text { Cells: death, proliferation (clusters), hypertrophy }\end{array}$} \\
\hline Grade 3: vertical fissures (clefts) & \multicolumn{4}{|c|}{$\begin{array}{l}\text { As above } \\
\text { Matrix vertical fissures into mid zone, branched fissures } \\
\pm \text { Cationic stain depletion (Safranin O or Toluidine Blue) into lower } 2 / 3 \text { of cartilage (deep zone) } \\
\pm \text { New collagen formation (polarized light microscopy, Picro Sirius Red stain) } \\
\text { Cells: death, regeneration (clusters), hypertrophy, cartilage domains adjacent to fissures }\end{array}$} \\
\hline Grade 4: erosion & \multicolumn{4}{|c|}{$\begin{array}{l}\text { Cartilage matrix loss: delamination of superficial layer, mid layer cyst formation } \\
\text { Excavation: matrix loss superficial layer and mid zone }\end{array}$} \\
\hline Grade 5: denudation & \multicolumn{4}{|c|}{$\begin{array}{l}\text { Surface: sclerotic bone or reparative tissue including fibrocartilage within denuded surface. Microfracture with } \\
\text { repair limited to bone surface }\end{array}$} \\
\hline Grade 6: deformation & \multicolumn{4}{|c|}{$\begin{array}{l}\text { Bone remodelling (more than osteophyte formation only). Includes: microfracturewith fibrocartilaginous and } \\
\text { osseous repair extending above the previous surface }\end{array}$} \\
\hline \multicolumn{5}{|c|}{ Grade $=$ depth progression into cartilage } \\
\hline \multicolumn{2}{|c|}{$\begin{array}{l}\text { stained with safranin-O and toluidine blue. Samples were } \\
\text { evaluated histologically based on the standard grading } \\
\text { and staging of OA cartilage histopathology [35]. Evalua- } \\
\text { tion was quantified with the following formula: most } \\
\text { degenerated site in the cartilage (grades } 1-6 \text {, Table } 2 \text { ) } \times \text { the } \\
\text { area of degeneration (stage } 1-4 \text {, Table } 3 \text { ) = OA score (1-24, } \\
\text { Table 3). }\end{array}$} & $\begin{array}{l}\text { Statistical anc } \\
\text { After analysis } \\
\text { were used for } \\
\text { OA scores wer } \\
\text { sidered signif } \\
\text { List of abbr } \\
\text { OA: osteoarth } \\
\text { oidal anti-inf }\end{array}$ & $\begin{array}{l}\text { iance, the least } \\
\text { oc testing (Sche } \\
\text { pared and valu } \\
\text { lons } \\
\text { HA: hyaluronic } \\
\text { atory drugs; BS }\end{array}$ & $\begin{array}{l}\text { icant differences } \\
\text { nethod). Average } \\
<0.05 \text { were con- } \\
\text { NSAIDs: nonster- } \\
\text { vine spongiform }\end{array}$ \\
\hline & \multicolumn{4}{|c|}{ Stage \% Involvement (surface, area, volume) } \\
\hline Grade (key feature) & Stage $1<10 \%$ & Stage $210-25 \%$ & Stage $325-50 \%$ & Stage $4>50 \%$ \\
\hline Grade I(surface intact) & 1 & 2 & 3 & 4 \\
\hline Grade 2 (surface discontinuity) & 2 & 4 & 6 & 8 \\
\hline Grade 3 (vertica fissures, clefts) & 3 & 6 & 9 & 12 \\
\hline Grade 4 (erosion) & 4 & 8 & 12 & 16 \\
\hline Grade 5(denudation) & 5 & 10 & 15 & 20 \\
\hline Grade 6(deformation) & 6 & 12 & 18 & 24 \\
\hline
\end{tabular}

Score $=$ grade $\times$ stage 
encephalopathy; ACL-T: anterior cruciate ligament transaction; EDTA: ethylene diaminetetraacetic acid; SAF: selfassembled film.

\section{Competing interests}

The authors declare that they have no competing interests.

\section{Authors' contributions}

$\mathrm{NO}, \mathrm{MS}$ and MK performed the research. NO and MS analyzed the data. NO took charge of the statistical analyses. MS, KU and JM wrote the manuscript. KU, TB, KT, MU and KK extracted the qniumucin from jellyfish. All authors have read and approved the final manuscript.

\section{Acknowledgements}

This research was partly supported by Grants-In-Aid for Scientific Research No. 17034067 in the Priority Area of "Molecular Nano Dynamics" and No. 17300166 and the High-Tech Research Center Project for Private Universities from the Ministry of Education, Culture, Sports, Science and Technology of Japan. The research was also supported by the project to develop "innovative seeds" (Creation and Support Program for Start-ups from Universities) of the Japanese Science and Technology Agency and the General Insurance Association of Japan, Mitsui Sumitomo Insurance Welfare Foundation.

\section{References}

I. Sato M, Mochida J: Osteoarthritis. Yakkyoku (Journal of Practical Pharmacy) 2007, 58:858-865.

2. American College of Rheumatology Subcommittee on Osteoarthritis Guidelines: Recommendations for the medical management of osteoarthritis of the hip and knee. Arthritis Rheum 2000, 43:1905-1915.

3. Huskisson EC, Berry H, Gishen P, Jubb RW, Whitehead J: Effects of antiinflammatory drugs on the progression of osteoarthritis of the knee. LINK study group. Longitudinal investigation of nonsteroidal antiinflammatory drugs in knee osteoarthritis. I Rheumatol 1995, 22:194|-1946.

4. Rashad S, Revell P, Hemingway A, Low F, Rainsford K, Walker F: Effect of non-steroidal anti-inflammatory drugs on the course of osteoarthritis. Lancet 1989, 2:5 19-522.

5. Dougados M, Gueguen A, Nguyen M, Berdah L, Lequesne M, Mazieres $B$, Vignon E: Radiological progression of hip osteoarthritis: definition, risk factors and correlations with clinical status. Ann Rheum Dis 1996, 55:356-362.

6. Reijman M, Bierma-Zeinstra SM, Pols HA, Koes BW, Stricker BH, Hazes JM: Is there an association between the use of different types of nonsteroidal anti-inflammatory drugs and radiologic progression of osteoarthritis? The Rotterdam Study. Arthritis Rheum 2005, 52:3137-3/42.

7. Petrella RJ, DiSilvestro MD, Hildebrand C: Effects of hyaluronate sodium on pain and physical functioning in osteoarthritis of the knee. A randomized, doubleblind, placebo-controlled clinical trial. Arch Intern Med 2002, 162:292-298.

8. Dougados $M$, Nguyen $M$, Listrat $V$, Amor B: High molecular weight sodium hyaluronate (hyalectin) in osteoarthritis of the knee: a I year placebo-controlled trial. Osteoarthritis Cartilage 1993, I:97-103.

9. Salk RS, Chang TJ, D'Costa WF, Soomekh DJ, Grogan KA: Sodium hyaluronate in the treatment of osteoarthritis of the ankle: a controlled, randomized, double-blind pilot study. J Bone Joint Surg Am 2006, 88:295-302.

10. Y Kobayashi Y, A Okamoto A, K Nishinari K: Viscoelasticity of hyaluronic acid with different molecular weights. Biorheology I994, 3 I:235-244.

II. Rhee DK, Marcelino J, Baker M, Gong Y, Smits P, Lefebvre V, Jay GD, Stewart M, Wang H, Warman ML, Carpten JD: The secreted glycoprotein lubricin protects cartilage surfaces and inhibits synovial cell overgrowth. J Clin Invest 2005, I I 5:622-63I.
12. Jay GD, Torres JR, Warman ML, Laderer MC, Breuer KS: The role of lubricin in the mechanical behavior of synovial fluid. Proc Natl Acad Sci USA 2007, 104:6194-6199.

13. Strous G], Dekker J: Mucin-type glycoproteins. Crit Rev Biochem Mol Biol 1992, 27:57-92.

14. Grundy MM, McKenzie JD, Richardson NV, Bavington CD, Mulloy B, Lever R, Page CP: Product from Starfish. US Patent No. 6991810 2000.

15. Kimura S, Gohda T, Sakurai Y: Characterization of nidamental mucin from Japanese common squid Todarodes pacificus. Tokyo Univ Fish 2003, 89:7-13.

16. Masuda A, Baba T, Dohmae N, Yamamura M, Wada H, Ushida K: Mucin (qniumucin), a glycoprotein from jellyfish and determination of its main chain structure. J Nat Prod 2007, 70: 1089-1092.

17. Konttinen YT, Saari H, Nordstrom DC: Effect of interleukin-I on hyaluronate synthesis by synovial fibroblastic cells. Clin Rheumatol 1991, 10:15I-154.

18. Schiavinato A, Lini E, Guidolin D, Pezzoli G, Botti P, Martelli M, Cortivo $\mathrm{R}, \mathrm{De}$ Galateo A, Abatangelo G: Intra-articular sodium hyaluronate injections in the Pond-Nuki experimental model of osteoarthritis in dogs. II. Clin Orthop Relat Res 1989, 241:286-299.

19. Chang DP, Abu-Lail NI, Guilak F, Jay GD, Zauscher S: Conformational mechanics, adsorption and normal force interactions of lubricin and hyaluronic acid on model surfaces. Langmuir 2008, 24:1 I83-1193.

20. Davidson HJ, Kuonen VJ: The tear film and ocular mucins. Vet Ophthalmol 2004, 7:7I-77.

21. Taylor ME: Introduction to Glycobiology Oxford: Oxford University Press; 2006

22. Glenister DA, Salamon KE, Smith K, Beighton D, Keevil CW Enhanced growth of complex communities of dental plaque bacteria in mucin-limited continuous culture. Microb Ecol Health Dis 1988, I:31-38.

23. Wu A, Csako G, Herp A: Structure, biosynthesis and function of salivary mucins. Mol Cell Biochem 1994, 137:39-55.

24. Hashimoto Y, Hashimoto S, Pigman W: Purification and properties of porcine submaxillary mucin. Arch Biochem Biophys 1964 , 104:282-29|.

25. Harding SE: An analysis of the heterogeneity of mucins. No evidence for a self-association. Biochem J 1984, 21 9: I06I-1064.

26. Imura $\mathrm{H}$, Mori $\mathrm{T}$, Ohkura $\mathrm{H}$, Ishii $\mathrm{M}$, Ariyoshi $\mathrm{H}$, Endo J, Kitao $\mathrm{M}$, Takeda I, Kobayashi H, Inoue M, Hirota M, Yanakido M, Hakomori S, Kannagi R: Basic and clinical evaluation of an immunoradiometric competitive inhibition assay for sialyl $T_{N}$ antigen; (I) Evaluation of assay conditions and normal values. Jpn J Cancer Chemother 1989, 16:3213-3219.

27. Adikwu MU, Alozie BU: Application of snail mucin dispersed in detarium gum gel in wound healing. Sci Res Essay 2007, 2:195-198.

28. Yoshioka M, Coutts RD, Amiel D, Hacker SA: Characterization of a model of osteoarthritis in the rabbit knee. Osteoarthritis Cartilage 1996, 4:87-98.

29. Hashimoto S, Takahashi K, Amiel D, Coutts RD, Lotz M: Chondrocyte apoptosis and nitric oxide production during experimentally induced osteoarthritis. Arthritis Rheum 1998, 4I: $1266-1274$.

30. Amiel D, Toyoguchi T, Kobayashi K, Bowden K, Amiel ME, Healey RM: Long-term effect of sodium hyaluronate (Hyalgan) on osteoarthritis progression in a rabbit model. Osteoarthritis Cartilage 2003, I I:636-643

3I. Jo H, Ahn HJ, Kim EM, Kim HJ, Seong SC, Lee I, Lee MC: Effects of dehydroepiandrosterone on articular cartilage during the development of osteoarthritis. Arthritis Rheum 2004, 50:2531-2538.

32. Batiste DL, Kirkley A, Laverty S, Thain LM, Spouge AR, Gati JS, Foster PJ, Holdsworth DW: High-resolution MRI and micro-CT in an ex vivo rabbit anterior cruciate ligament transection model of osteoarthritis. Osteoarthritis Cartilage 2004, 12:6| 4-626.

33. Boulocher C, Duclos ME, Arnault F, Roualdes O, Fau D, Hartmann DJ, Roger T, Vignon E, Viguier E: Knee joint ultrasonography of the ACLT rabbit experimental model of osteoarthritis: relevance and effectiveness in detecting meniscal lesions. Osteoarthritis Cartilage 2008, 16:470-479.

34. Jean YH, Wen ZH, Chang YC, Hsieh SP, Lin JD, Tang CC, Chen WF, Chou AK, Wong CS: Increase in excitatory amino acid concentration and transporters expression in osteoarthritis knee of 
anterior cruicate ligament transected rabbits. Osteoarthritis Cartilage 2008, 16: I 442-1449.

35. Pritzker KP, Gay S, Jimenez SA, Ostergaard K, Pelletier JP, Revell PA, Salter D, Berg WB van den: Osteoarthritis cartilage histopathology: grading and staging. Osteoarthritis Cartilage 2006, 14:13-29.

Publish with Biomed Central and every scientist can read your work free of charge

"BioMed Central will be the most significant development for disseminating the results of biomedical research in our lifetime. " Sir Paul Nurse, Cancer Research UK

Your research papers will be:

- available free of charge to the entire biomedical community

- peer reviewed and published immediately upon acceptance

- cited in PubMed and archived on PubMed Central

- yours - you keep the copyright
BioMedcentral 